\title{
Preparación y caracterización de compuestos de inclusión entre Rh(III), Ni(II), 2-acetil piridina tiosemicarbazonas y $\beta$-ciclodextrina
}

\author{
Jorge Ivan Daza ${ }^{1}$, Pedro F. B. Brandão ${ }^{2}$ Ana Esperanza Burgos ${ }^{1, *}$ \\ ${ }^{1}$ Grupo de Investigación en Química de Coordinación y Bioinorgánica, Departamento de Química, \\ Facultad de Ciencias, Universidad Nacional de Colombia, Bogotá, Colombia \\ ${ }^{2}$ Laboratorio de Microbiología Ambiental y Aplicada, Departamento de Química, \\ Facultad de Ciencias, Universidad Nacional de Colombia, Bogotá, Colombia
}

\section{Resumen}

En este trabajo se describe la preparación y caracterización de los compuestos de inclusión entre el ligante 2-acetilpiridina tiosemicarbazona (HAPTSC) y los complejos cloruro de bis(2-acetilpiridina tiosemicarbazona) rodio(III), [Rh(HAPTSC) $\left.)_{2}\right]_{3}$, y cloruro de bis(2-acetilpiridina tiosemicarbazona)níquel(II), [Ni(HAPTSC) ${ }_{2}$ ] $\mathrm{Cl}_{2}$, con $\beta$-ciclodextrina ( $\left.\beta C D\right)$ como estrategia para mejorar la solubilidad y la actividad antimicrobiana de estos compuestos. Estos compuestos fueron preparados en razón molar 1:1 entre el respectivo compuesto y la $\beta C D$. Fueron caracterizados por espectroscopia de resonancia magnética nuclear protónica y carbono-13 (RMN ${ }^{1} \mathrm{H},{ }^{13} \mathrm{C}$ ), espectroscopia de absorción en la región de infrarrojo (IR), análisis térmico (DTA/DSC) y difracción de rayos X en polvo (DRX). Los resultados obtenidos a través de estas técnicas indican la formación de los compuestos de asociación y/o inclusión parcial entre el ligante y los complejos metálicos de Rh(III) y $\mathrm{Ni}(\mathrm{II})$ con $\beta \mathrm{CD}$. Se realizaron ensayos antimicrobianos de los complejos metálicos incluidos, como también de los compuestos libres frente a bacterias Gram-negativas (Escherichia coli, Pseudomonas aeruginosa) y Gram-positivas (Staphylococcus aureus, Bacillus subtilis) y dos levaduras (Candida albicans y Saccharomyces cerevisiae). La comparación de la actividad antimicrobiana de los complejos incluidos en $\beta C D$ con la actividad de los compuestos libres mostró que para el ligante incluido la actividad aumentó contra $S$. aureus, mientras que para el compuesto de inclusión de Rh(III) aumentó contra P. aeruginosa.

Palabras Clave: complejos de Rh(III), Complejos de Ni(II), Ciclodextrinas, 2-acetilpiridina tiosemicarbazona, Actividad antimicrobiana.

Preparation and characterization of inclusion compounds between rh(iii), ni(ii), 2-acetyl pyridine thiosemicarbazones and $\beta$-cyclodextrin

\begin{abstract}
In this paper the preparation and characterization of inclusion compounds between 2-acetylpyridine thiosemicarbazone ligand (HAPTSC) and the complexes bis(2-acetylpyridine thiosemicarbazone)rhodium(III) chloride, $\left[\mathrm{Rh}(\mathrm{HAPTSC})_{2}\right] \mathrm{Cl}_{3}$, and bis (2-acetylpyridine thiosemicarbazone)nickel(II) chloride, [Ni(HAPTSC) ${ }_{2}$ ] $\mathrm{Cl}_{2}$, with $\beta$-cyclodextrin $(\beta C D)$ as a strategy to improve the solubility and antimicrobial activity of these compounds. These compounds were prepared in a molar ratio 1:1 between the respective compound and $\beta C D$, and characterized by protonic nuclear magnetic resonance and carbon-13 $\left(\mathrm{NMR}{ }^{1} \mathrm{H},{ }^{13} \mathrm{C}\right)$ spectroscopy, absorption in the infrared (IR) region spectroscopy, thermal analysis (DTA/DSC) and X-ray diffraction in powder (XRD). The results obtained through these techniques indicate the formation of association compounds and/or partial inclusion between the ligant and the $\mathrm{Rh}$ (III) and $\mathrm{Ni}$ (II) metal complexes with $\beta \mathrm{CD}$. Antimicrobial assays were carried out with the enclosed metal complexes and the free compounds against Gram-negative (Escherichia coli, Pseudomonas aeruginosa) and Gram-positive (Staphylococcus aureus, Bacillus subtilis) bacteria and two yeast (Candida albicans and Saccharomyces cerevisiae). The comparison of the antimicrobial activity of the $\beta C D$ enclosed complex with the activity of the free compounds showed that the enclosed ligant increased its activity against $S$. aureus, whereas the enclosed Rh(III) compound increased its activity against P. aeruginosa.
\end{abstract}

Key words: Complexes of Rh(III), Complexes of Ni(II), Cyclodextrins, 2-acetylpyridine thiosemicarbazone, Biological activity. 


\section{Introducción}

Las tiosemicarbazonas y sus complejos con metales de transición son consideradas de gran interés químico y biológico, porque presentan diversas propiedades farmacológicas, que incluyen antineoplásica, antibacteriana, antifúngica, antiviral, antimalárica (Beraldo \& Gambino, 2004; Tenório et al., 2005; Beraldo, 2004; Gupta, 1994; Reis et al., 2010). Asimismo, muchos complejos de Rh(III) y Ni(II) con ligantes que presentan en su estructura átomos de $\mathrm{N}$ y $\mathrm{S}$ donores como en el caso de las tiosemicarbazonas, presentan actividad biológica antitumoral, antibacteriana, antifúngica, antiviral y antimalarica (Kasuga et al., 2001; Beraldo \& Gambino, 2004; Beraldo, 2004; Tenório et al., 2005; Krishnan et al., 2008; Lobana, Sharma, Bawa y Khanna, 2009; Tamayo, Burgos y Brandão, 2014), lo que ha impulsado notablemente el estudio de este tipo de compuestos.

Las ciclodextrinas (CDs) son oligosacáridos cíclicos constituidos por unidades de glucopiranosa, unidas a través de enlaces $\alpha(1-4)$. Las ciclodextrinas más importantes son la $\alpha \mathrm{CD}, \beta C D$ y $\gamma \mathrm{CD}$, formadas por 6,7 y 8 unidades de glucosa, respectivamente. Las CDs presentan una estructura en forma de cono truncado (hueco). Este tipo de estructura presenta una cavidad de carácter hidrofóbico y apolar, que permite incluir una gran variedad de moléculas en solución acuosa como en fase sólida (Szejtli, 1998; Del Valle, 2004; Kayaci, Ertas y Uyar, 2013a Kettel, Schaefer, Groll y Moeller, 2014;). Cuando se forman estos compuestos de inclusión, se pueden modificar las propiedades físico-químicas y biológicas de las moléculas huéspedes (Burgos, Belchior y Sinisterra, 2002; Burgos, Okio y Sinisterra, 2012; Kayaci, Umu, Tekinay y Uyar, 2013b), como en el caso de los compuestos de Rh(III), $\mathrm{Ni}(\mathrm{II})$, con el ligante 2-acetilpiridina tiosemicarbazona.

Este trabajo describe la preparación y caracterización de los compuestos de inclusión parcial y/o asociación entre la $\beta C D$ y los complejos de coordinación $\left[\mathrm{Rh}(\mathrm{HAPTSC})_{2}\right]_{\mathrm{Cl}_{3}}$ y [Ni(HAPTSC) $]_{2} \mathrm{Cl}_{2}$, como del ligante HAPTSC, los cuales fueron usados como moléculas huésped. Además, se estudió la actividad antimicrobiana de los compuestos de inclusión y se comparó con la de los compuestos libres. La actividad antimicrobiana de los compuestos sintetizados fue evaluada frente a bacterias Gram-positivas y Gram-negativas y dos cepas de levaduras.

\section{Materiales y métodos}

\section{Síntesis del ligante 2-acetilpiridina tiosemicarbazona (HAPTSC)}

El compuesto 2-acetilpiridina se sintetizó siguiendo los protocolos indicados en la literatura por Anderson, Duca y Scudi (1952) y por Klayman et al. (1979). Se disolvieron en

\footnotetext{
*Correspondencia:

Ana Esperanza Burgos, aeburgosc@unal.edu.co

Recibido: 5 de marzo de 2015

Aceptado: 2 de julio de 2015
}

etanol cantidades estequiométricas en proporción molar 1:1 de 2-acetilipiridina y tiosemicarbazida, se adicionaron cuatro gotas de ácido acético glacial y se dejó bajo reflujo durante 4 h. Se obtuvo una solución de color amarillo brillante, fue enfriada en baño de hielo, se formó un precipitado de color blanco, se filtró y se lavó con agua caliente para retirar los precursores que no habían reaccionado. El compuesto fue secado en un desecador al vacío durante 12 h. El ligante 2-acetilpiridina tiosemicarbazona presentó un rendimiento de reacción del $60 \%$, con un punto de fusión entre $159^{\circ} \mathrm{C}$ y $160^{\circ} \mathrm{C}$. El compuesto obtenido presenta características similares a las reportadas en la literatura (Anderson, et al., 1952; Klayman et al., 1979).

El ligante 2-acetilpiridina tiosemicarbazona en la región ultravioleta-visible presenta tres bandas características entre 200 y $320 \mathrm{~nm}$, con coeficientes de extinción molar mayores a $1000 \mathrm{M}^{-1} \mathrm{~cm}^{-1}$, para las transiciones tipo $\pi \rightarrow \pi^{*}$ del anillo piridínico de la tiosemicarbazona. Otras posibles transiciones en la molécula son las $n \rightarrow \pi^{*}$ debido a la presencia de átomos con pares de electrones libres, sus coeficientes de extinción molar se encuentran entre 10 y 100 $\mathrm{M}^{-1} \mathrm{~cm}^{-1}$, no se observan debido a que estas absorciones son de baja intensidad comparadas con las $\pi \rightarrow \pi^{*}$ (Skoog, Holler y Nieman, 2001). Al comparar los valores experimentales con los que se encuentran reportados en la literatura (KovalaDemertzi et al., 2001), se observa que las bandas aparecen a longitudes de onda similares y los coeficientes de extinción molar $(\varepsilon)$ se encuentran en el intervalo de valores esperados, indicando la obtención del ligante.

\section{Síntesis del complejo de coordinación [Rh(HAPTSC) $]_{2} \mathrm{Cl}_{3}$}

El compuesto de coordinación de rodio(III) fue sintetizado por métodos modificados relatados en la literatura por Offiong y Martelli (Offiong \& Martelli, 1997). Se disolvieron cantidades estequiométricas en proporción molar 1:2 de cloruro de rodio(III) y 2-acetilpiridina tiosemicarbazona en etanol absoluto. La solución fue dejada bajo reflujo y agitación constante durante 24 h. Se obtuvo un precipitado de color naranja oscuro, fue filtrado, lavado con éter etílico y secado en un desecador al vacío durante $12 \mathrm{~h}$.

El cloruro de bis(2-acetilpiridina tiosemicarbazona)rodio(III) en la región ultravioleta-visible, presenta una banda característica a $318 \mathrm{~nm}$, con coeficiente de extinción molar de $44976 \mathrm{M}^{-1} \mathrm{~cm}^{-1}$, característica de transiciones electrónicas del metal del HOMO (orbital molecular ocupado de más alta energía, Highest Occupied Molecular Orbital) al LUMO (orbital molecular no ocupado de más baja energía, Lowest Unoccupied Molecular Orbital) por influencia del ligante en la estructura, correspondiente a transferencia de carga entre el ligante 2-acetilpiridina tiosemicarbazona y el metal central. Estos resultados obtenidos fueron muy similares en magnitud a los que se encuentran reportados en la literatura (Offiong \& Martelli, 1997; Kovala-Demertzi et al., 2001; Skoog et al., 2001). 
El momento magnético efectivo ( $\mu$ eff) para el cloruro de bis(2-acetilpiridina tiosemicarbazona)rodio(III) fue obtenido por triplicado y su valor promedio fue $0,75 \mathrm{MB}$ a $19^{\circ} \mathrm{C}$. Cuando se compara con el valor esperado para un compuesto de una configuración electrónica $\mathrm{d}^{6}(\mathrm{~S}=0)$ se obtiene un $\mu$ eff de $0 \mathrm{MB}$, al aplicar la ecuación $\mu_{\text {eff }}=\sqrt{(n(n+2)}$. Si presentara un electrón desapareado, aplicando la misma ecuación, se obtiene un $\mu$ eff de 1,72 MB, lo cual está muy lejos del valor obtenido experimentalmente, indicando que la especie es diamagnética. Este resultado indica que el Rh(III) en el complejo sintetizado tiene una configuración de spin bajo (campo alto en teoría de campo cristalino).

\section{Síntesis del complejo de coordinación [Ni(HAPTSC) $\left.{ }_{2}\right]_{C_{2}}$}

El compuesto de coordinación de níquel(II) fue sintetizado por el método relatado en la literatura por Kasuga et al. (2001) para ser usado como molécula huésped en la preparación de compuestos de inclusión y/o asociación. Se disolvieron en etanol cantidades estequiométricas en proporción molar 1:2 de cloruro de níquel(II) y 2-acetilpiridina tiosemicarbazona, la solución fue dejada bajo reflujo con agitación constante durante $3 \mathrm{~h}$. Se obtuvo un precipitado café naranja. Se filtró y lavó con éter etílico, hasta obtener un filtrado incoloro, el compuesto se secó en un desecador al vacío durante $12 \mathrm{~h}$.

El cloruro de bis(2-acetilpiridina tiosemicarbazona)níquel(II) presenta dos bandas características en la región ultravioleta visible. Una banda fue observada a $372 \mathrm{~nm}$ asignada a la transición de los electrones del metal del HOMO al LUMO por influencia del ligante en la estructura. La otra banda en $292 \mathrm{~nm}$ asignada a la transición de los electrones $\pi$ del anillo piridínico de la estructura de la tiosemicarbazona tipo $\pi \rightarrow \pi^{*}$. Las bandas de absorción en el ultravioleta-visible obtenidas para este complejo son similares a las reportadas en la literatura Kasuga et al. (2001).

El momento magnético efectivo ( $\mu$ eff) para el cloruro de bis(2-acetilpiridina tiosemicarbazona)níquel(II) fue determinado por triplicado y el valor promedio fue de 3,20 MB a $19{ }^{\circ} \mathrm{C}$. Cuando se compara con el valor reportado en la literatura (2,88 MB a $25^{\circ} \mathrm{C}$; Kasuga et al., 2001), este valor corresponde con el valor teórico esperado para un compuesto que tenga una configuración electrónica d $\mathrm{d}^{8}, \mathrm{~S}=1$ ( $\mathrm{S}$ momento magnético de spin).

\section{Preparación de los compuestos de inclusión con $\beta$-ciclodextrina}

Los compuestos de inclusión parcial y/o asociación fueron preparados por métodos modificados descritos en la literatura (Sinisterra, Shastri, Najjar y Langer, 1999; Burgos et al., 2002; Da Silva, Empis y Teixeira-Dias, 2002; Calderini \& Pessine, 2008; Burgos \& Sinisterra, 2010; Burgos et al., 2012). Se disolvieron cantidades estequiométricas $1: 1$ del complejo metálico de Rh(III), con $\beta C D$, en $20 \mathrm{~mL}$ de agua deionizada. La mezcla fue dejada bajo agitación constante por $24 \mathrm{~h}$, a temperatura ambiente. La solución fue congelada en nitrógeno líquido y liofilizada durante $48 \mathrm{~h}$, hasta obtener el sólido correspondiente. El mismo procedimiento de preparación anterior fue usado para el complejo de $\mathrm{Ni}(\mathrm{II})$ y el ligante 2 -acetilpiridina tiosemicarbazona (HAPTSC) con $\beta C D$.

Para efectos de comparación, se preparó una mezcla física en relación molar 1:1 entre el complejo de $\mathrm{Rh}(\mathrm{III})$ y la $\beta \mathrm{CD}$. Los sólidos fueron triturados separadamente en un mortero de ágata y luego mezclados hasta obtener una disolución sólida homogénea. También fue preparada de la misma manera descrita anteriormente la mezcla física para el complejo de $\mathrm{Ni}(\mathrm{II})$ con la $\beta \mathrm{CD}$ ([Ni(HAPTSC) $\left.]_{2} \mathrm{Cl}_{2} / \beta \mathrm{CD}\right)$ y para el ligante 2-acetilpiridina tiosemicarbazona con $\beta C D$.

\section{Caracterización de los compuestos}

La caracterización de los compuestos obtenidos en este trabajo se realizó por diferentes técnicas espectroscópicas y propiedades físico-químicas. Los puntos de fusión de las muestras fueron obtenidos en un equipo Mel-Temp II (Laboratoy Devices Inc.). Los espectros ultravioleta-visible (UV-visible) fueron obtenidos en un equipo Nanodrop 2000c Spectrophotometer (Thermo Scientific) en cubeta de cuarzo de $1 \mathrm{~cm}$ de paso óptico. Los espectros de absorción en la región de infrarrojo (IR) fueron obtenidos en un equipo Nicolet iS10 Spectrometer (Thermo Fisher Scientific) en pastillas de $\mathrm{KBr}$ y en el rango de 4000 a 400 $\mathrm{Cm}^{-1}$. Los espectros ${ }^{1} \mathrm{H}-\mathrm{RMN}$ y ${ }^{13} \mathrm{C}-\mathrm{RMN}$ y el experimento de ${ }^{13} \mathrm{C}$ DEPT-135 fueron obtenidos en un espectrofotómetro Bruker Avance 400 (400 MHz), empleando como solvente DMSO-d ${ }_{6}$ y TMS como patrón interno. La susceptibilidad magnética de los compuestos de coordinación fue obtenida en un equipo Magnetic Susceptibility Balance (Alfa Aesar). Los análisis de las muestra por TGA/DSC se realizaron en un equipo Rheometrics STA 500 (Rheometrics Scientific Inc.), en atmósfera de argón y a una rampa de calentamiento de $10{ }^{\circ} \mathrm{C} / \mathrm{min}$. La cantidad de muestra utilizada para las curvas TGA y DSC fue de $2.5 \mathrm{mg}$. Los análisis de las muestras por medio de difracción de rayos X en polvo (DRX) fueron obtenidos en un difractómetro de rayos X Panalytical X'pert Pro MPD (Pananalytical B.V.) con una radiación $\mathrm{CuK} \alpha$ de $1,5405 \AA$, en ángulo $2 \Theta$ variando de 4 a 60 grados.

\section{Ensayos de actividad antimicrobiana de los compuestos}

Los ensayos de actividad antimicrobiana fueron evaluados por MIC (concentración mínima inhibitoria), según Kasuga et al. (2001). Se usaron como microorganismos de prueba cuatro bacterias, dos de tipo Gram-negativa (Escherichia coli ATCC 25922 y Pseudomonas aeruginosa sp) y dos de tipo Gram-positiva (Bacillus subtilis sp. y Staphylococcus aureus ATCC 29213), así como dos levaduras (Candida albicans ATCC 10231 y Saccharomyces cerevisiae NRRL-Y 12843). El método utilizado fue la difusión radial en cajas de Petri con medio de cultivo respectivo para cada tipo de microorganismo: para bacterias se utilizó agar de soya tríptica (Tryptic Soy Agar-TSA, Scharlau) y para levaduras se usó agar papa dextrosa (Potato Dextrose Agar-PDA, Merck). 
Se tomaron $100 \mu \mathrm{L}$ de suspensión de microorganismo en solución salina $0,9 \% \mathrm{p} / \mathrm{v}$ con una densidad óptica $(660 \mathrm{~nm})$ entre 0,1 y 0,2 (que corresponde a una concentración de células en la escala de McFarland de 0,5) y con un rastrillo de vidrio se esparció por toda la superficie de la caja con el medio de cultivo respectivo para el microorganismo estudiado, dejándose secar. Luego se abrieron siete pozos en el agar con un sacabocados estéril de $3 \mathrm{~mm}$ de diámetro (uno en el centro y los otros seis concéntricos a este, cercanos a la pared de la caja de Petri) para sembrar las muestras de los compuestos a probar, disueltas en una solución que contiene $30 \%$ de etanol, $3 \%$ de DMSO y $5 \%$ de etilenglicol para los compuestos de Ni(II) libre e incluido, Rh(II) incluido y el ligante incluido en la $\beta C D$ y en DMSO para el compuesto de $\mathrm{Rh}(\mathrm{III})$ libre parcialmente soluble y el ligante 2-acetilpiridina tiosemicarbazona insolubles en agua. En cada pozo exterior se sembraron $100 \mu \mathrm{L}$ de solución patrón de cada compuesto en el rango de concentraciones entre 1000 y 100 ppm (las concentraciones trabajadas fueron 1000, 750, 500, 250, 125 y 100 ppm respectivamente) y en el pozo central se sembró $50 \mu \mathrm{L}$ de un antibiótico como control positivo (para las bacterias E. coli, B. subtilis y S. aureus se utilizó como control cefalotina $40 \mathrm{mg} / \mathrm{mL}$; para $P$. aeruginosa se utilizó como control ciprofloxacina $0,3 \%$; para las levaduras se utilizó como control el clotrimazol 1\%). Se dejaron las cajas de Petri en incubadora durante el tiempo necesario para el crecimiento del microorganismo respectivo (24 h para las bacterias a $35-37^{\circ} \mathrm{C}$ y $48 \mathrm{~h}$ para las levaduras a $20^{\circ} \mathrm{C}$ ) y se midieron los halos de inhibición formados en cada pozo. La mínima concentración inhibitoria (MIC) fue determinada por la menor concentración en la cual se presentó inhibición en el crecimiento del microorganismo estudiado.

\section{Resultados y discusión}

El espectro de IR del compuesto de inclusión parcial y/o asociación, entre el $\left[\mathrm{Rh}(\mathrm{HAPTSC})_{2}\right] \mathrm{Cl}_{3}$ y $\beta \mathrm{CD}$ ([Rh(HAPTSC) $)_{2} \mathrm{Cl}_{3} / \beta \mathrm{CD}$ ) (Figura 1S, http://www.raccefyn. co/index.php/raccefyn/article/downloadSuppFile/204/1004), mostró un afinamiento de las bandas en 3400 a $3100 \mathrm{~cm}^{-1}$ y 1150 a $1000 \mathrm{~cm}^{-1}$ atribuidas a los estiramientos $v(-\mathrm{O}-\mathrm{H})$ y $v(-\mathrm{C}-\mathrm{O}-\mathrm{C})$, respectivamente cuando fue comparado con el espectro de la mezcla física y la $\beta C D$. Además, las bandas de la $\beta C D$ en torno de 1630 y $1300-1400 \mathrm{~cm}^{-1}$ asignadas a la deformación de $\delta(\mathrm{OH})$ y $\delta(\mathrm{C}-\mathrm{H})$ no fueron observadas. También, la disminución en la intensidad de las bandas del compuesto de coordinación de $\mathrm{Rh}(\mathrm{III})$ en $1600 \mathrm{~cm}^{-1}$ correspondiente a los estiramientos $v(-\mathrm{C}=\mathrm{N})$ y en 900 a 700 $\mathrm{cm}-1$ correspondientes a la tensión $v(-\mathrm{C}=\mathrm{S})$. Estos resultados sugieren la formación de compuestos de inclusión parcial y/o asociación, mediante interacciones intermoleculares y la formación de puentes de hidrógeno entre el bis(2acetilpiridina tiosemicarbazona)rodio(III) con la $\beta C D$ de tipo hospedero-huésped (host-guess). El afinamiento de estas bandas ocurre tanto en los compuestos de asociación como en la mezcla física, sugiriendo que estos compuestos presentan, también en estado sólido, asociaciones de tipo hospedero-huésped por la parte externa de la $\beta \mathrm{CD}$ a través de interacciones débiles de tipo van der Waals, dipolo-dipolo y enlaces de hidrógeno (Sinisterra, Shastri, Najjar y Langer, 1999; Burgos et al., 2002; De Sousa et al., 2008; Burgos \& Sinisterra, 2010; Burgos et al., 2012).

Los espectros de infrarrojo de la $\beta \mathrm{CD}$, del [Ni(HAPTSC) ${ }_{2}$ ] $\mathrm{Cl}_{2}$, de su compuesto de asociación y su mezcla física, los de HAPTSC, su respectivo compuesto de asociación como el de su mezcla física, mostraron comportamientos similares descritos anteriormente para el $\left[\mathrm{Rh}(\mathrm{HAPTSC})_{2}\right] \mathrm{Cl}_{3}$.

Las curvas TGA y DSC de la $\beta C D$, muestran dos eventos térmicos bien definidos. El primero, debido a la salida de aproximadamente 11 moléculas de agua, entre $30^{\circ} \mathrm{C}$ y $120^{\circ} \mathrm{C}$ con un máximo en $80^{\circ} \mathrm{C}$. Estas moléculas están localizadas en la cavidad como aguas de inclusión y entre las moléculas de las CDs, como aguas intersticiales, manteniendo la estructura de la $\beta C D$ (Kohata, Jyodoi y Ohyoshi, 1993; Sinisterra et al., 1999; Giordano, Novak y Moyano, 2001; Burgos et al., 2002; De Sousa et al., 2008; Burgos \& Sinisterra, 2010; Burgos et al., 2012). En seguida de este evento, la curva TGA de la $\beta C D$ muestra estabilidad térmica hasta temperaturas de $300^{\circ} \mathrm{C}$. El segundo evento térmico, entre $280^{\circ} \mathrm{C}$ y $370^{\circ} \mathrm{C}$, con un máximo en $320^{\circ} \mathrm{C}$, asociado a la pérdida de masa del $86 \%$ aproximadamente, correspondiente a la descomposición del anillo glicosídico de la $\beta C D$, con formación de residuos carbonizados (Kohata et al., 1993; Giordano et al., 2001; Burgos et al., 2002; Burgos \& Sinisterra, 2010; Burgos et al., 2012). Estos mismos fenómenos térmicos son también observados en la curva DSC entre $80^{\circ} \mathrm{C}$ y $320^{\circ} \mathrm{C}$, como eventos endotérmicos, debido a la pérdida de moléculas de agua y la descomposición de la $\beta C D$.

La curva TGA para el complejo [Rh(HAPTSC) $\left.{ }_{2}\right]_{3} l_{3}$ (Figura 2S, http://www.raccefyn.co/index.php/raccefyn/article/ downloadSuppFile/204/1005), presenta una pérdida de masa del $5 \%$, entre $30^{\circ} \mathrm{C} \mathrm{y} 100^{\circ} \mathrm{C}$ que corresponde a la salida de aproximadamente 2 moléculas de agua de hidratación del complejo. Se observa otro evento entre $120^{\circ} \mathrm{C}$ y $250^{\circ} \mathrm{C}$, correspondiente a la pérdida del $38 \%$ de masa, asociado con la fusión y descomposición parcial del complejo de $\mathrm{Rh}(\mathrm{III})$. Este complejo continúa perdiendo masa constante hasta $500^{\circ} \mathrm{C}$, que corresponde a la descomposición del complejo hasta dejar un residuo del 19\% correspondiente probablemente al Rh metálico.

La curva TGA para el compuesto de inclusión parcial y/o asociación del $\mathrm{Rh}(\mathrm{III})$, muestra tres eventos bien definidos. A temperaturas entre $30^{\circ} \mathrm{C} \mathrm{y} 120^{\circ} \mathrm{C}$, con una pérdida de masa del $11 \%$, correspondiente a la salida de aproximadamente 13 moléculas de agua. De ellas, 11 moléculas de agua corresponden a la $\beta \mathrm{CD}$ y 2 al complejo metálico. Este resultado sugiere la formación de interacciones de lado de afuera de la $\beta C D$ formando un compuesto de asociación con el complejo metálico. Se verifica otro evento térmico 
entre $150^{\circ} \mathrm{C}$ y $234^{\circ} \mathrm{C}$, con una pérdida de masa del $15 \%$, que corresponde a la descomposición del complejo metálico de $\mathrm{Rh}(\mathrm{III})$ libre. A partir de $234^{\circ} \mathrm{C}$ hasta aproximadamente $360^{\circ} \mathrm{C}$, se observa una pérdida de masa relacionada con termodescomposición del complejo y de la $\beta \mathrm{CD}$ en el complejo de asociación formado. Este resultado indica la formación de interacciones de fuerzas de van der Waals y enlaces de hidrógeno cuando se forma el compuesto de asociación entre la $\beta C D$ y el complejo metálico de $\mathrm{Rh}(\mathrm{III})$. Se obtiene un residuo del $17 \%$ correspondiente posiblemente al rodio metálico. Cuando se compara la curva TGA del compuesto de asociación del Rh(III) con el de la mezcla física (Figura 2), se observa un comportamiento térmico similar, sugiriendo que en estado sólido el complejo [Rh(HAPTSC) $\left.{ }_{2}\right]_{C_{3}}$ sufre interacciones débiles con la $\beta$-CD, hospedero-huésped. También, se observa una mayor estabilidad térmica cuando se compara el residuo obtenido de asociación del complejo de Rh(III) con el obtenido en la termodescomposición de la $\beta C D$ libre y la mezcla física, y menor estabilidad térmica cuando se compara con $\left[\mathrm{Rh}(\mathrm{HAPTSC})_{2}\right] \mathrm{Cl}_{3}$ libre, sugiriendo nuevas interacciones $\beta C D$-complejo de Rh(III).

La curva DSC (Figura 1) del compuesto de asociación del $\left[\mathrm{Rh}(\mathrm{HAPTSC})_{2}\right]_{\mathrm{Cl}_{3}}$, presenta tres eventos térmicos. El primero está relacionado con la salida de las moléculas de agua. El segundo y tercer evento endotérmico, asociado con la fusión y termodescomposición del compuesto de asociación. La curva DSC de la mezcla física, comparada con la del compuesto de asociación de Rh(III), muestra un perfil de termodescomposición similar, pero se evidencia la aparición de un pico endotérmico a $287^{\circ} \mathrm{C}$, que corresponde a la termodescomposición de la $\beta C D$ libre. Estos resultados sugieren que en estado sólido se forman interacciones débiles entre las moléculas del complejo de Rh(III) con la $\beta C D$.

Analizando la curva TGA (Figura 3S, http://www.raccefyn. co/index.php/raccefyn/article/downloadSuppFile/204/ 1006), del $\left[\mathrm{Ni}(\mathrm{HAPTSC})_{2}\right] \mathrm{Cl}_{2}$, el compuesto presenta estabilidad en el intervalo de temperatura entre $25^{\circ} \mathrm{C}$ a $200^{\circ} \mathrm{C}$, la descomposición térmica del compuesto ocurre en dos eventos: entre $200^{\circ} \mathrm{C}$ y $380^{\circ} \mathrm{C}$, se presenta una pérdida de masa del $52 \%$, debida a la termodescomposición parcial del compuesto. A partir de $480^{\circ} \mathrm{C}$, se presenta otra pérdida de masa, de aproximadamente el $35,5 \%$, asociado con la termodescomposición total del complejo metálico, quedando como residuo probablemente el metal.

La curva TGA para el compuesto de asociación y/o inclusión parcial del Ni(II) (Figura 3S), muestra una pérdida de masa del $12 \%$, a una temperatura entre $50^{\circ} \mathrm{C}$ y $110^{\circ} \mathrm{C}$, corresponde a la salida de 11 moléculas de agua. Este resultado sugiere que el complejo metálico no se encuentra dentro de la cavidad de la $\beta \mathrm{CD}$, formando un compuesto de inclusión, si no fuera de ella formando un compuesto de asociación. Se presenta una segunda pérdida de masa del $77 \%$, entre $180^{\circ} \mathrm{C}$ y $354^{\circ} \mathrm{C}$, que corresponde a la fusión y degradación del anillo de la $\beta$-ciclodextrina, seguido de la descomposición del compuesto. A partir de esta temperatura continua la pérdida de masa constante, hasta quedar un residuo del $5 \%$ correspondiente al metal.

Cuando se comparan las curvas TGA para el compuesto de asociación del Ni(II) y la mezcla física (Figura 3S), se observa un comportamiento térmico semejante. Esto es debido, a que cuando estas dos moléculas entran en contacto, ocurre entre ellas algún tipo de interacciones muy débiles como de van der Waals o enlaces de hidrógeno (Kohata et al., 1993; Burgos et al., 2002; De Sousa et al., 2008; Burgos \& Sinisterra, 2010; Burgos et al., 2012). Además, se observa mayor estabilidad térmica cuando se compara el residuo obtenido de la termodescomposición del compuesto de asociación del $\mathrm{Ni}(\mathrm{II})$ con el de la $\beta \mathrm{CD}$ libre y menos estabilidad térmica, cuando se compara con el complejo de $\mathrm{Ni}(\mathrm{II})$ libre y la mezcla física, sugiriendo la formación de nuevas interacciones entre la $\beta \mathrm{CD}$ y el complejo de $\mathrm{Ni}(\mathrm{II})$ asociado.

La curva DSC para el compuesto de coordinación de níquel(II) (Figura 2), presenta un pico endotérmico con un mínimo a una temperatura de $284^{\circ} \mathrm{C}$, que corresponde

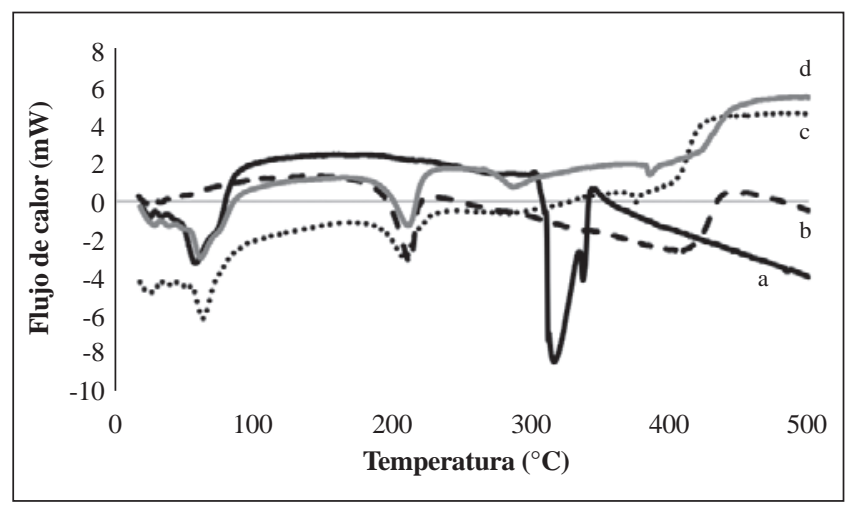

Figura 1. Curvas DSC para: a. $\beta C D$ (negra), b. [Rh(HAPTSC) $)_{2}$ $\mathrm{Cl}_{3}$ (discontinua), c. compuesto de asociación [Rh(HAPTSC) $\left.{ }_{2}\right]_{3} /$ $\beta C D$ (punteada), d. mezcla física gris).

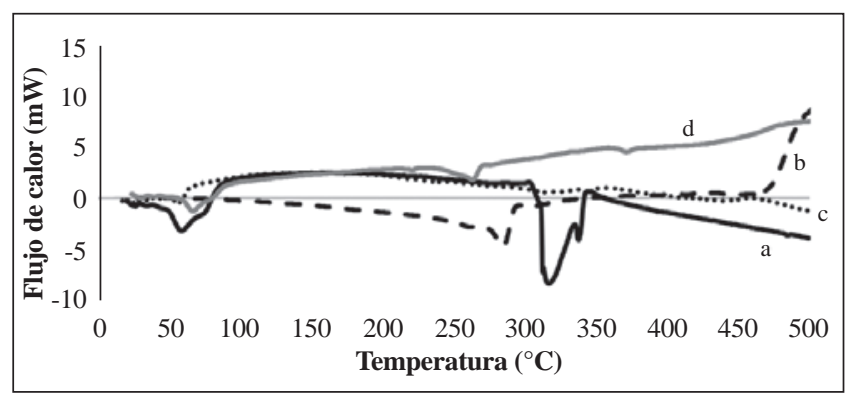

Figura 2. Curvas DSC para: a. $\beta \mathrm{CD}$ (negra), b. $\left[\mathrm{Ni}(\mathrm{HAPTSC})_{2}\right] \mathrm{Cl}_{2}$ (discontinua), c. compuesto de asociación [Ni(HAPTSC) $\left.{ }_{2}\right] \mathrm{Cl}_{2} / \beta \mathrm{CD}$ (punteada), d. mezcla física (gris). 
a la termodescomposición del compuesto de coordinación de Ni(II); este resultado obtenido es corroborado con los resultados encontrados en la curva de TGA para este compuesto (Figura 3S).

La curva DSC del compuesto de asociación del bis(2acetilpiridina tiosemicarbazona)Ni(II) (Figura 2), presenta un pico endotérmico, asociado a la pérdida de moléculas de agua y otro evento endotérmico, indicando la formación de nuevas interacciones entre este compuesto y la $\beta C D$. Cuando se compara la curva DSC del compuesto de asociación con la curva DSC de la mezcla física, se observa un comportamiento diferente en su termodescomposición. Las curvas DTG y DSC de la mezcla física del complejo metálico de Ni(II) (Figura 2 y Figura 3S), se pueden interpretar como una superposición de las curvas de los componentes libres.

La curva TGA del ligante 2-acetilpiridina tiosemicarbazona (Figura 4S, http://www.raccefyn.co/index.php/raccefyn/ article/downloadSuppFile/204/1007), presenta una pérdida de masa del $4 \%$ aproxi-madamente, a $100^{\circ} \mathrm{C}$, que corresponde a la molécula de agua de hidratación (Steiner \& Koellner, 1994; Giordano et al., 2001; Burgos et al., 2002; Burgos \& Sinisterra, 2010; Burgos et al., 2012) seguida de una estabilidad térmica entre $100^{\circ} \mathrm{C}$ a $180^{\circ} \mathrm{C}$. A partir de $180^{\circ} \mathrm{C}$ se presenta una pérdida de masa del $84 \%$ aproximadamente, asociada a la fusión y descomposición del ligante.

La curva TGA del compuesto de asociación del ligante 2 -acetilpiridina tiosemicarbazona con la $\beta$-ciclodextrina (Figura 4S) presenta una primera pérdida de masa de aproximadamente el $14 \%$ a una temperatura aproximadamente a $120^{\circ} \mathrm{C}$, que corresponde a la pérdida de 12 moléculas de agua: 11 pertenecen a la $\beta C D$ y la otra, el agua de hidratación del ligante. Estos resultados sugieren la formación de un compuesto de asociación entre la $\beta C D$ y el ligante 2-acetilpiridina tiosemicarbazona. Luego se presenta una pérdida de masa de $9 \%$ entre $180^{\circ} \mathrm{C}$ y $250^{\circ} \mathrm{C}$, que corresponde a la termodescomposición del ligante libre. La pérdida de masa de $86 \%$ aproximadamente, entre $270^{\circ} \mathrm{C}$ y $370^{\circ} \mathrm{C}$, corresponde a la descomposición del ligante junto con la termodescomposición de la $\beta C D$ en el compuesto de asociación formado, sugiriendo la formación de interacciones de puentes de hidrógeno y fuerzas débiles entre el ligante y la ciclodextrina en el compuesto de asociación.

Cuando fueron comparadas las curvas TGA del compuesto de asociación con la curva TGA de la mezcla física entre el ligante 2-acetilpiridina tiosemicarbazona y la $\beta$-ciclodextrina, se observó que el perfil de termodescomposición fue muy similar. Estos resultados sugieren que en estado sólido (mezcla física), se generan fuerzas intermoleculares entre la $\beta C D$ y ligante HAPTSC.

La curva de DSC de la 2-acetilpiridina tiosemicarbazona (Figura 3), presenta un primer evento endotérmico a $90^{\circ} \mathrm{C}$, que indica la pérdida de agua de hidratación, que corrobora el resultado obtenido con la curva TGA (Figura 4S). Se presenta un segundo evento endotérmico a $156^{\circ} \mathrm{C}$ aproximadamente, que corresponde posiblemente al punto de fusión del ligante. El tercer pico endotérmico, a una temperatura de $196^{\circ} \mathrm{C}$ indica la descomposición del compuesto.

La curva DSC del compuesto de asociación entre el ligante 2 -acetilpiridina tiosemicarbazona con la $\beta C D$, presenta un evento endotérmico que está relacionado con la salida de las moléculas de agua de inclusión e hidratación a temperaturas menores a $100^{\circ} \mathrm{C}$, con un mínimo a $68^{\circ} \mathrm{C}$, el segundo y tercer evento, endotérmico a temperaturas de $161^{\circ} \mathrm{C}$ y $330^{\circ} \mathrm{C}$ respectivamente, relacionados con la fusión seguida de la descomposición del compuesto de asociación. Comparando la curva DSC obtenida para el compuesto de asociación con la curva DSC de la mezcla física entre el ligante 2-acetilpiridina tiosemicarbazona y la $\beta C D$ (Figura 3), ambas curvas de DSC presentan un comportamiento de degradación térmica similar, lo cual indica que en estado sólido existen interacciones entre las moléculas, como enlaces de hidrógeno, de van der Waals y dipolo-dipolo.

\section{Difracción de rayos $\mathrm{X}$ (DRX)}

Al comparar el patrón de difracción de la $\beta C D$, que presenta un sistema policristalino (Figura 4), el complejo de Rh(III) y la mezcla física con el patrón de difracción del

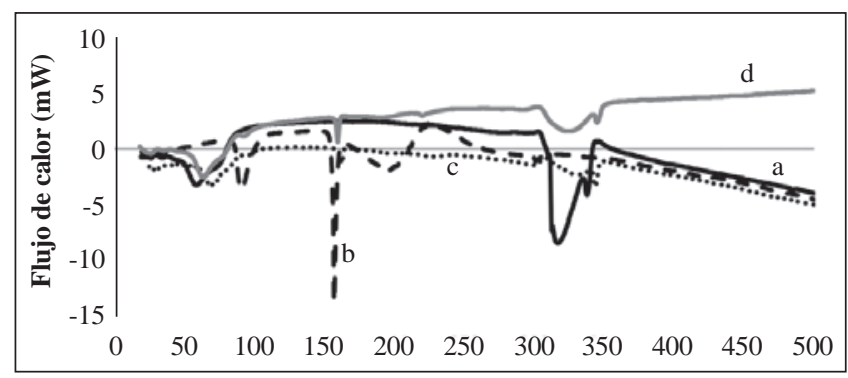

Figura 3. Curvas DSC para: a. $\beta C D$ (negra), b. HAPTSC (discontinua), c. compuesto de asociación HAPTSC/ßCD (punteada), d. mezcla física (gris).

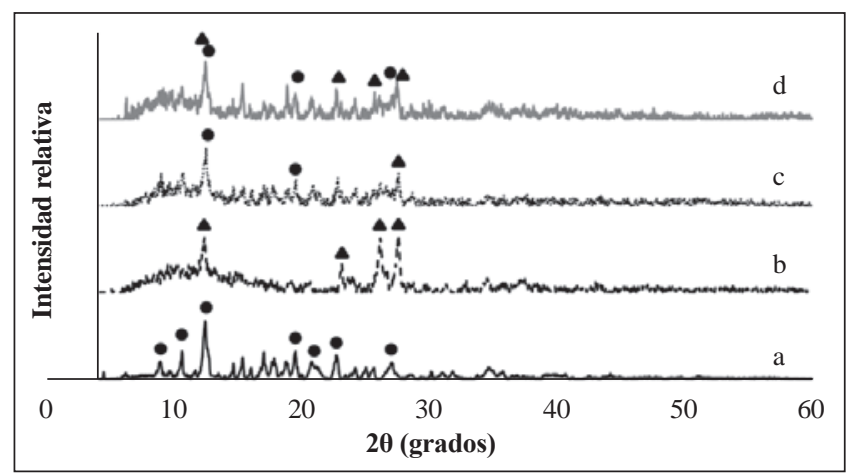

Figura 4. Difractogramas de rayos $X$ para: a. $\beta C D$ (negra), $b$. [Rh(HAPTSC) $)_{2} \mathrm{Cl}_{3}$ (discontinua), c. compuesto de asociación $\left[\mathrm{Rh}(\mathrm{HAPTSC})_{2}\right] \mathrm{Cl}_{3} / \beta \mathrm{CD}$ (punteada), d. mezcla física (gris). 
compuesto de asociación y/o inclusión parcial, se verifica que en el compuesto de asociación están ausentes gran cantidad de picos característicos de los compuestos libres y no aparecen nuevos, sugiriendo una estructura diferente, debido a la existencia de interacciones de tipo van der Waals, interacciones hidrofóbicos y electrostáticas o enlaces de hidrógeno cuando se forma el compuesto de asociación. Por otro lado, cuando son comparados los patrones de difracción de la $\beta C D$ con la mezcla física, presenta un comportamiento diferente al compuesto de asociación, interpretándose como una "superposición" de los compuestos libres, $\beta C D$ y complejo de Rh(III).

Fue observado un comportamiento similar cuando se compararon los patrones de difracción del compuesto de asociación del $\mathrm{Ni}(\mathrm{II})$ con la mezcla física. Se observó también, una disminución en las intensidades relativas de los picos de la $\beta C D$, debido a la formación del compuesto de asociación (Figura 5).

Cuando se compara el patrón de difracción del compuesto de asociación con el patrón de difracción de la $\beta C D$, que es un sistema policristalino, el ligante HAPTSC y la mezcla física (Figura 6), se confirma que en el compuesto de asociación están ausentes varios picos característicos de los compuestos libres y la aparición de otros nuevos (Steiner \& Koellner, 1994; Sinisterra et al., 1999; Burgos et al., 2002; Burgos \& Sinisterra, 2010; Burgos et al., 2012). También, se observa una disminución en las intensidades relativas de las señales de la $\beta C D$, sugiriendo la presencia de interacciones tipo van der Waals, enlaces de hidrógeno y dipolo-dipolo. El difractograma de la mezcla física no presenta una "superposición" de los compuestos libres, de la $\beta C D$ y el ligante HAPTSC, también presenta la desaparición de algunos de los picos característicos de la $\beta C D$, lo que sugiere la formación de interacciones tipo puente de hidrógeno entre la ciclodextrina y el ligante 2-acetilpiridina tiosemicarbazona en el estado sólido.

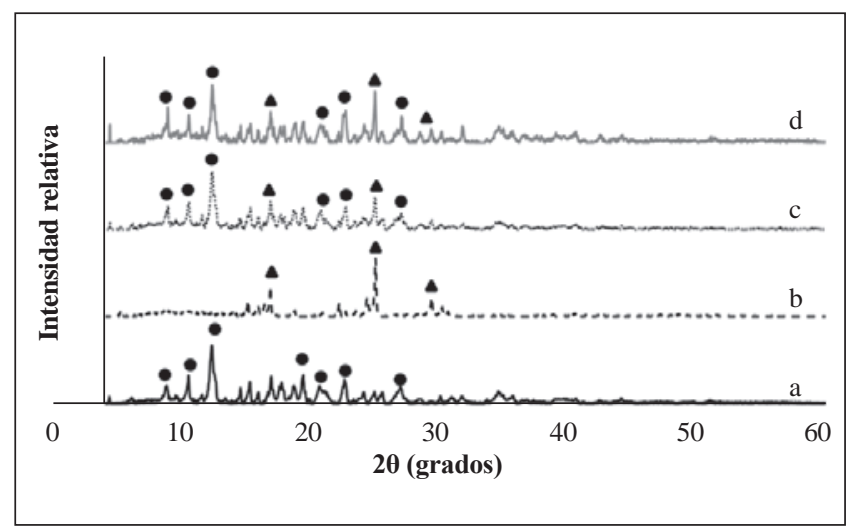

Figura 5. Difractogramas de rayos $X$ para: a. $\beta C D$ (negra), b. $\left[\mathrm{Ni}(\mathrm{HAPTSC})_{2}\right] \mathrm{Cl}_{2}$ (discontinua), c. compuesto de asociación $\left[\mathrm{Ni}(\mathrm{HAPTSC})_{2}\right]_{\mathrm{Cl}_{2}} / \beta \mathrm{CD}$ (punteada), d. mezcla física (gris).

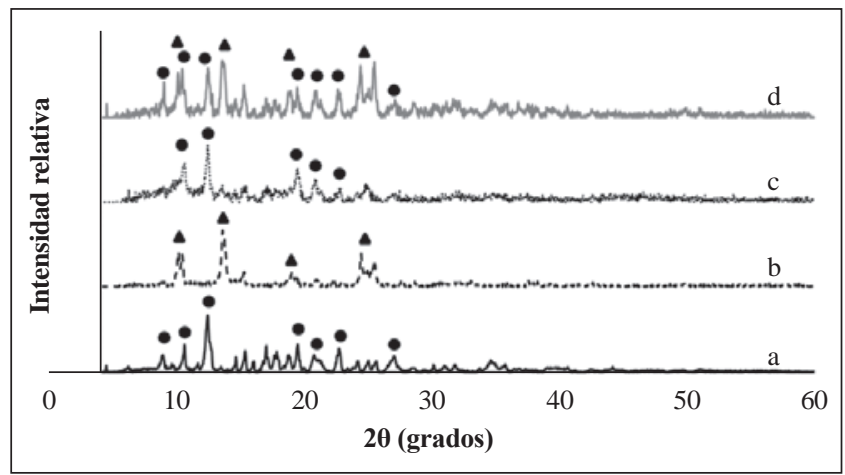

Figura 6. Difractogramas de rayos $X$ para: a. $\beta C D$ (negra), b. HAPTSC (discontinua), c. compuesto de asociación HAPTSC)/ $\beta C D$ (punteada), d. mezcla física (gris).

\section{Resonancia Magnética Nuclear}

Los desplazamientos químicos de $\mathrm{RMN}$ de ${ }^{1} \mathrm{H}$ y ${ }^{13} \mathrm{C}$ de la $\beta C D$ y del compuesto de asociación de Rh(III), son presentados en las Tablas 1 y 2. Las atribuciones fueron realizadas con base en los datos reportados en la literatura (Inoue, 1993; Poveda \& Jiménez-Barbero, 1998; Burgos et al., 2002; Burgos et al., 2012; Burgos \& Sinisterra, 2010).

En la Tabla 1, se muestran las señales de $\mathrm{RMN}-{ }^{1} \mathrm{H}$ de los espectros y sus asignaciones para el compuesto de asociación de $\mathrm{Rh}(\mathrm{III})$, el [Rh(HAPTSC) $\left.{ }_{2}\right]_{3} l_{3}$ libre y la $\beta \mathrm{CD}$. Al comparar los desplazamientos químicos de las señales de los hidrógenos del compuesto de asociación de Rh(III) con los del complejo [Rh(HAPTSC) ${ }_{2} \mathrm{Cl}_{3}$ libre, se observan variaciones de $\delta$ en todos los hidrógenos del complejo de Rh(III), siendo los más acentuados para los $\mathrm{H}_{1}, \mathrm{H}_{2}, \mathrm{H}_{3}, \mathrm{H}_{8}$, $\mathrm{H}_{9}$ y $\mathrm{H}_{10}(\Delta \mathrm{d}=0,05 \mathrm{ppm}, 0,11 \mathrm{ppm}, 0,12 \mathrm{ppm}, 0,10 \mathrm{ppm}$, $0,22 \mathrm{ppm}$ y 0,07 ppm, respectivamente). Este resultado explica la interacción del anillo piridínico y la tioamida del compuesto de coordinación de Rh(III) con la $\beta C D$. Cuando se comparan los desplazamientos químicos de las señales de los protones para compuesto de asociación y la $\beta C D$, se observan pequeñas variaciones de $\delta$ en todos los hidrógenos en el compuesto de asociación, siendo los más acentuados para los hidrógenos $\mathrm{H}_{3}, \mathrm{H}_{4}$ y $\mathrm{H}_{5}$ del anillo de la ciclodextrina y no se observan las señales de los hidrógenos asociados a los hidroxilos primarios y secundarios. Esto permite suponer las interacciones y formación de enlaces de hidrógeno con los hidroxilos del lado de afuera de la $\beta C D$ y el complejo metálico. Los hidrógenos $\mathrm{H}_{3}$ y $\mathrm{H}_{5}$ se encuentran en el interior de la cavidad de la $\beta C D$ y el $\mathrm{H}_{4}$ y los hidroxilos primarios y secundarios del lado de fuera de la cavidad de la $\beta C D$ (Figura 7), sugiriendo interacciones de tipo hospedero-huésped en la parte interna y externa de la cavidad, formando los respectivos compuestos de inclusión parcial y/o asociación (Inoue, 1993; Wenz, 1994; Poveda \& Jiménez-Barbero, 1998; Burgos et al., 2002; Ribero, Carvalho, Ferreira y Veiga, 2005; Burgos \& Sinisterra, 2010; Burgos et al., 2012). 
Tabla 1. Valores de desplazamientos químicos $(\delta)$ de hidrógenos, cambios en los desplazamientos químicos $(\Delta \delta)$ para $\beta C D$, HAPTSC, $\left[\mathrm{Rh}(\mathrm{HAPTSC})_{2}\right] \mathrm{Cl}_{3}, \mathrm{HAPTSC} / \beta \mathrm{CD}$ y $\left[\mathrm{Rh}(\mathrm{HAPTSC})_{2}\right] \mathrm{Cl}_{3} / \beta \mathrm{CD}$ y valores de desplazamientos químicos ${ }^{13} \mathrm{C}$ para estos compuestos.

\begin{tabular}{|c|c|c|c|c|c|}
\hline \multirow{2}{*}{$\begin{array}{l}\text { Asignación de } \\
\text { señales en RMN }\end{array}$} & \multicolumn{5}{|c|}{ Desplazamiento químico ( $\delta$ en ppm) y cambio de desplazamiento químico ( $\Delta \delta$ en ppm) } \\
\hline & $\beta C D$ & HAPTSC & {$\left[\mathrm{Rh}(\mathrm{HAPTSC})_{2}\right] \mathrm{Cl}_{3}$} & HAPTSC/ $\beta$ CD & {$\left[\mathrm{Rh}(\mathrm{HAPTSC})_{2}\right] \mathrm{Cl}_{3} / \mathbf{B C D}$} \\
\hline $\mathrm{H}_{1}$ & ------ & 8,57 & $8,79 \quad(0,22)$ & 8,57 & $8,74(-0,05)$ \\
\hline $\mathrm{H}_{2}$ & ----- & 7,38 & $7,87 \quad(0,49)$ & $7,39(0,01)$ & $7,76(-0,11)$ \\
\hline $\mathrm{H}_{3}$ & ----- & 7,78 & $8,41 \quad(0,63)$ & $7,79(0,01)$ & $8,29(-0,12)$ \\
\hline $\mathrm{H}_{4}$ & ------ & 8,42 & $8,41 \quad(-0,01)$ & 8,42 & $8,42(0,01)$ \\
\hline $\mathrm{H}_{5}$ & ----- & 2,38 & $2,42 \quad(0,04)$ & 2,38 & $2,40(-0,02)$ \\
\hline $\mathrm{H}_{6}$ & ------ & 2,38 & $2,42 \quad(0,04)$ & 2,38 & $2,40(-0,02)$ \\
\hline $\mathrm{H}_{7}$ & ------ & 2,38 & $2,42 \quad(0,04)$ & 2,38 & $2,40(-0,02)$ \\
\hline $\mathrm{H}_{8}$ & ----- & 10,32 & $10,81 \quad(0,49)$ & 10,32 & $10,71(-0,10)$ \\
\hline $\mathrm{H}_{9}$ & ------ & 8,42 & $8,86 \quad(0,44)$ & 8,42 & $8,64(-0,22)$ \\
\hline $\mathrm{H}_{10}$ & ----- & 8,14 & $8,71 \quad(0,57)$ & 8,14 & $8,64(-0,07)$ \\
\hline $\mathrm{C}_{1}$ & ----- & 148,88 & $145,98 \quad(-2,91)$ & $148,89(0,01)$ & ----- \\
\hline $\mathrm{C}_{2}$ & ----- & 124,40 & $125,16 \quad(0,76)$ & $124,41(0,01)$ & ------ \\
\hline $\mathrm{C}_{3}$ & ------ & 136,82 & $131,89 \quad(-4,94)$ & $136,83(0,01)$ & ----- \\
\hline $\mathrm{C}_{4}$ & ----- & 121,35 & $128,67 \quad(7,32)$ & $121,36(0,01)$ & ----- \\
\hline $\mathrm{C}_{5}$ & ----- & 155,19 & $134,53(-20,66)$ & 155,19 & ----- \\
\hline $\mathrm{C}_{6}$ & ------ & 148,72 & $147,24 \quad(-1,30)$ & $148,71(-0,01)$ & ----- \\
\hline $\mathrm{C}_{7}$ & ------ & 12,57 & $18,95 \quad(6,38)$ & $12,56(-0,01)$ & ------ \\
\hline $\mathrm{C}_{8}$ & ----- & 179,62 & $146,92(-32,70)$ & $179,60(-0,02)$ & ----- \\
\hline $\mathrm{CD} \mathrm{H}_{1}$ & 4,83 & ----- & ------ & 4,83 & $4,82(-0,01)$ \\
\hline $\mathrm{CD} \mathrm{H}_{2}$ & 3,31 & ----- & ------ & $3,30(-0,01)$ & $3,29(-0,02)$ \\
\hline $\mathrm{CD} \mathrm{H}_{3}$ & 3,62 & ------ & ------ & 3,62 & $3,65(0,03)$ \\
\hline $\mathrm{CD} \mathrm{H}_{4}$ & 3,56 & ------ & ------ & $3,55(-0,01)$ & $3,34(-0,22)$ \\
\hline $\mathrm{CD} \mathrm{H}_{5}$ & 3,59 & ----- & ------ & $3,58(-0,01)$ & $3,54(-0,05)$ \\
\hline $\mathrm{CD} \mathrm{H}_{6}$ & 3,64 & ----- & ----- & $3,63(-0,01)$ & $3,63(-0,01)$ \\
\hline $\mathrm{CD} \mathrm{H}_{6}^{\prime}$ & 3,64 & ------ & ------ & $3,63(-0,01)$ & $3,63(-0,01)$ \\
\hline $\mathrm{CD} \mathrm{OH}_{2}$ & 4,44 & ----- & ----- & $4,49(0,05)$ & ------ \\
\hline $\mathrm{CD} \mathrm{OH}_{3}$ & 5,66 & ------ & ------ & $5,69(0,03)$ & ----- \\
\hline $\mathrm{CD} \mathrm{OH}_{6}$ & 5,70 & ----- & ----- & $5,74(0,04)$ & ------ \\
\hline $\mathrm{CD} \mathrm{C}_{1}$ & 102,42 & ------ & ------ & 102,42 & $101,86(-0,56)$ \\
\hline $\mathrm{CD} \mathrm{C}_{2}$ & 72,90 & ----- & ------ & 72,90 & $72,35(-0,55)$ \\
\hline $\mathrm{CD} \mathrm{C}_{3}$ & 73,53 & ------ & ----- & 73,53 & $72,98(-0,55)$ \\
\hline $\mathrm{CD} \mathrm{C}_{4}$ & 82,04 & ------ & ------ & 82,04 & $81,46(-0,58)$ \\
\hline $\mathrm{CD} \mathrm{C}_{5}$ & 72,52 & ----- & ------ & $72,53(0,01)$ & $71,97(-0,55)$ \\
\hline $\mathrm{CD} \mathrm{C}_{6}$ & 60,41 & ------ & ------ & $60,42(0,01)$ & $59,85(-0,56)$ \\
\hline
\end{tabular}

En la Tabla 1, se presentan los desplazamientos químicos de las señales de $\mathrm{RMN}$ de ${ }^{13} \mathrm{C}$ de la $\beta C D$ y del compuesto de asociación de Rh(III). Cuando se comparan las señales de los espectros del compuesto de asociación con $\beta C D$ libre, todas las señales de carbono se desplazan en una proporción similar. Las asignaciones de las señales en el espectro de RMN de C-13 están basadas en los cambios químicos, de las señales para el átomo de carbono en el complejo, cuando se compara con el espectro del ligante libre, $\Delta \delta=\delta$ (complejo) - $\delta$ (free ligante libre). Estos 
Tabla 2. Concentración mínima inhibitoria (CMI) de los compuestos HAPTSC, [Rh(HAPTSC) $)_{2} \mathrm{Cl}_{3},\left[\mathrm{Ni}_{(\mathrm{HAPTSC}} \mathrm{HCl}_{2}\right.$ libres y sus respectivos compuestos de inclusión HAPTSC/ $\beta \mathrm{CD}$, $\left[\mathrm{Rh}(\mathrm{HAPTSC})_{2}\right] \mathrm{Cl}_{3} / \beta \mathrm{CD}$ y $\left[\mathrm{Ni}(\mathrm{HAPTSC})_{2}\right] \mathrm{Cl}_{2} / \beta \mathrm{CD}$ contra bacterias $(\mathrm{Gram}$ positivas y Gram-negativas) y levaduras por el método de difusión radial. Se muestra también la CMI de las sales de Ni y Rh, y de la $\beta$-ciclodextrina $(\beta C D)$.

\begin{tabular}{|c|c|c|c|c|c|c|}
\hline \multirow{3}{*}{ Compuestos } & \multicolumn{6}{|c|}{ Concentración Mínima Inhibitoria (CMI) en $\mu \mathrm{g} / \mathrm{mL}$ contra microorganismos } \\
\hline & \multicolumn{2}{|c|}{ Bacterias Gram-positivas } & \multicolumn{2}{|c|}{ Bacterias Gram-negativas } & \multicolumn{2}{|c|}{ Levaduras } \\
\hline & B. subtilis & S. aureus & E. coli & P. aeruginosa & S. cerevisiae & C. albicans \\
\hline HAPTSC libre & 500 & 250 & 250 & 1000 & 1000 & 1000 \\
\hline $\mathrm{NiCl}_{2} * 6 \mathrm{H}_{2} \mathrm{O}$ & - & - & - & - & 500 & 500 \\
\hline $\mathrm{RhCl}_{3} * \mathrm{xH}_{2} \mathrm{O}$ & - & - & - & - & 500 & 250 \\
\hline$\left[\mathrm{Ni}(\mathrm{HAPTSC})_{2}\right] \mathrm{Cl}_{2}$ libre & - & - & - & - & - & - \\
\hline$\left[\mathrm{Rh}(\mathrm{HAPTSC})_{2}\right] \mathrm{Cl}_{3}$ libre & - & 250 & - & 1000 & - & 250 \\
\hline$\beta$-ciclodextrina $(\beta C D)$ & - & - & - & - & - & - \\
\hline HAPTSC/ $\beta C D$ & - & 125 & - & - & - & 1000 \\
\hline$\left[\mathrm{Ni}(\mathrm{HAPTSC})_{2}\right] \mathrm{Cl}_{2} / \beta \mathrm{CD}$ & - & - & - & - & - & - \\
\hline$\left[\mathrm{Rh}(\mathrm{HAPTSC})_{2}\right] \mathrm{Cl}_{3} / \beta \mathrm{CD}$ & - & - & - & 750 & - & 1000 \\
\hline
\end{tabular}

Todos los halos de inhibición con diámetro igual o superior a 1,5 cm fueron considerados como efecto positivo de inhibibición del compuesto sobre el microorganismo probado. Halos de inhibición de controles: ciprofloxacina $0,3 \%$ ( $5 \mathrm{~cm}$, P. aeruginosa), cefalotina $40 \mu \mathrm{g} / \mathrm{mL}$ ( $4 \mathrm{~cm}, E$. coli; $1,5 \mathrm{~cm}, B . \mathrm{subtilis}$; $4 \mathrm{~cm}$, S. aureus), clotrimazol $1 \%$ (2,5 cm, S. cerevisiae y C. albicans). -, sin inhibición en el rango de concentraciones evaluadas.

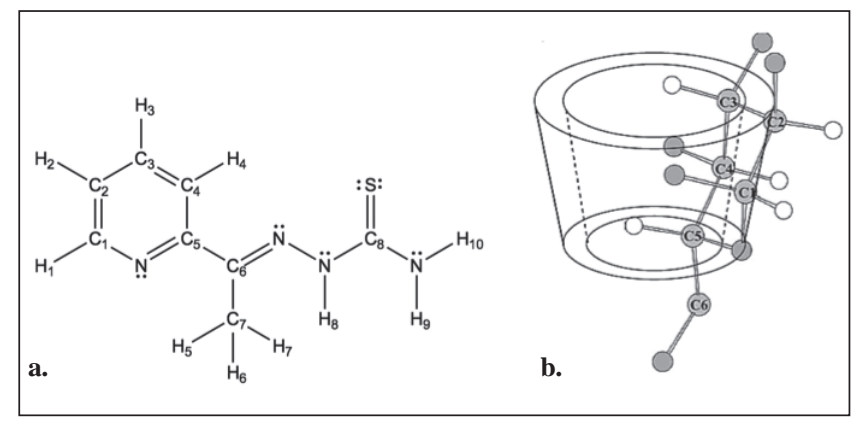

Figura 7. a. Estructura del ligante 2-acetilpiridina tiosemicarbazona, b. Estructura de la $\beta$-ciclodextrina.

resultados corroboran con los obtenidos por rayos X, IR, curvas TGA y DSC, donde se sugiere la formación de un compuesto de inclusión parcial y/o asociación.

\section{Pruebas de actividad antimicrobiana}

La actividad antimicrobiana del ligante HAPTSC y sus complejos de $\left[\mathrm{Rh}(\mathrm{HAPTSC})_{2}\right]_{\mathrm{Cl}_{3}}$ y $\left[\mathrm{Ni}(\mathrm{HAPTSC})_{2}\right] \mathrm{Cl}_{2}$ libres, así como los respectivos compuestos de inclusión parcial y/o asociación con la $\beta C D$ presentaron un comportamiento diferenciado (Tabla 2). El ligante HAPTSC libre presentó mayor actividad para las bacterias grampositiva $S$. aureus y gram-negativa E. coli (ambas con CMI $250 \mu \mathrm{g} / \mathrm{mL}$ ), seguido de actividad contra B. subtilis (CMI $500 \mu \mathrm{g} / \mathrm{mL}$ ) y P. aeruginosa (CMI $1000 \mu \mathrm{g} / \mathrm{mL}$ ). Así mismo, este compuesto presentó actividad contra las levaduras probadas (CMI $1000 \mu \mathrm{g} / \mathrm{mL}$ ). La sal de $\mathrm{Ni(II),}$ precursora para el complejo, presentó actividad contra las levaduras S. cerevisiae y C. albicans (CMI $500 \mu \mathrm{g} /$ $\mathrm{mL}$ ); la sal de Rh(III) también presentó actividad para las mismas dos levaduras (respectivamente, CMI $500 \mu \mathrm{g} / \mathrm{mL}$ y CMI $250 \mu \mathrm{g} / \mathrm{mL}$ ). Entre los complejos libres, únicamente el complejo [Rh(HAPTSC) $\left.{ }_{2}\right]_{C_{3}}$ presentó actividad y con mayor incidencia contra la bacteria gram-positiva $S$. aureus y la levadura C. albicans (ambos con CMI $250 \mu \mathrm{g} / \mathrm{mL}$ ). La $\beta C D$ no mostró cualquier efecto negativo contra los microorganismos probados. Los compuestos de inclusión en $\beta C D$ que mostraron actividad fueron el HAPTSC/ $\beta C D$ contra S. aureus y C. albicans (CMI $125 \mu \mathrm{g} / \mathrm{mL}$ y CMI 1000 $\mu \mathrm{g} / \mathrm{mL}$, respectivamente) y el complejo $\left[\mathrm{Rh}(\mathrm{HAPTSC})_{2}\right] \mathrm{Cl}_{3} /$ $\beta C D$ contra $P$. aeruginosa y $C$. albicans (respectivamente, CMI $750 \mu \mathrm{g} / \mathrm{mL}$ y CMI $1000 \mu \mathrm{g} / \mathrm{mL}$ ).

Los resultados sugieren que las actividades de los compuestos de 2-acetilpiridina tiosemicarbazona estudiados tienen comportamientos disimiles al coordinarse al metal o con la formación de los compuestos de inclusión respectivos. En general la actividad antimicrobiana de los diferentes compuestos libres probados disminuyó o se mantuvo constante en los complejos y compuestos de inclusión con $\beta C D$ (Tabla 2). La excepción fue para el HAPTSC que aumentó su actividad contra $S$. aureus cuando fue incluido en $\beta C D$ (pasó de CMI $250 \mu \mathrm{g} / \mathrm{mL}$ a CMI $125 \mu \mathrm{g} / \mathrm{mL}$ ) y contra $P$. aeruginosa cuando formó el compuesto de inclusión con rodio (pasó de CMI $250 \mu \mathrm{g} / \mathrm{mL}$ a CMI $125 \mu \mathrm{g} / \mathrm{mL}$ ). La variabilidad en la actividad antimicrobiana de los compuestos estudiados contra los diferentes microorganismos depende de la permeabilidad de las células (Sharma, Srivastava y Srivastava, 2007), ya que la coordinación del metal con la tiosemicarbazona aumenta su lipofilicidad en tanto que el 
compuesto de inclusión con la ciclodextrina aumenta su hidrofilicidad, haciendo que el sitio de acción del compuesto de coordinación sea más o menos accesible. En los casos en que se observó una mejora en la actividad antimicrobiana del ligante HAPTSC libre o en el compuesto de inclusión del $\mathrm{Rh}(\mathrm{III})$ en $\beta C D$, esto podría ser debido a que la inclusión facilita el transporte del compuesto a través de la membrana y hacia el sitio de acción adentro de la célula. Con relación al modo de acción antimicrobiano del complejo $\left.\mathrm{Rh}(\mathrm{HAPTSC})_{2}\right] \mathrm{Cl}_{3}$ con la célula, este podría involucrar la interacción del grupo azometino con los centros activos de constituyentes celulares a través de puentes de hidrógeno resultando en la interferencia con procesos celulares normales (Sharma et al., 2007).

Ningún compuesto evaluado pudo superar la actividad antimicrobiana mostrada por la cefalotina. Sin embargo, se resalta que el ligante HAPTSC libre y el complejo $\left[\mathrm{Rh}(\mathrm{HAPTSC})_{2}\right]_{\mathrm{Cl}_{3}}$ libre e incluido en $\beta \mathrm{CD}$ mostraron una actividad comparable a la del control de ciprofloxacina utilizado. Se destaca la actividad biológica de los compuestos que tuvieron acción contra las levaduras evaluadas, ya que en todos donde se observó actividad antimicrobiana, esta fue superior a la acción del control de Clotrimazol utilizado.

\section{Conclusiones}

Fueron preparados tres nuevos compuestos de asociación y/o inclusión parcial entre el ligante 2-acetilpiridina tiosemicarbazona, cloruro de bis(2-acetilpiridina tiosemicarbazona) rodio(III) y cloruro de bis(2-acetilpiridina tiosemicarbazona) níquel(II) con la $\beta$-ciclodextrina en relación molar 1:1.

Los resultados obtenidos por RMN protónica y carbono 13, para el ligante HAPTSC y complejo de Rh(III), Ni(II) y su respectivos compuestos de asociación y/o inclusión parcial, mostraron modificaciones importantes, que permiten sugerir la formación de compuestos de inclusión parcial entre estos compuestos con la $\beta \mathrm{CD}$.

Los ensayos biológicos indicaron que el ligante HAPTSC libre mostró actividad antimicrobiana contra todos los microorganismos probados. La coordinación al $\mathrm{Rh}(\mathrm{III})$ y la formación de su respectivo compuesto de inclusión, así como la formación del compuesto de inclusión con el ligante mostraron un incremento en la actividad contra algunos de los microorganismos probados, sugiriendo que estos pueden servir como una estrategia efectiva para mejorar la actividad antibacterial y anfúngica de las tiosemicarbazonas.

\section{Información suplementaria}

Figura 1S. Espectros de IR (pastilla de $\mathrm{KBr}$ ) de los compuestos: a. $\beta \mathrm{CD}$ (negra), b. $\left[\mathrm{Rh}(\mathrm{HAPTSC})_{2}\right] \mathrm{Cl}_{3}$ (discontinua), c. $\left[\mathrm{Rh}(\mathrm{HAPTSC})_{2}\right] \mathrm{Cl}_{3} / \beta \mathrm{CD}$ (punteada), d. mezcla física (gris).

Figura 2S. Curvas TGA para: a. $\beta C D$ (negra), b. [Rh(HAPTSC) $\left.{ }_{2}\right]$ $\mathrm{Cl}_{3}$ (discontinua), c. compuesto de asociación [Rh(HAPTSC) ${ }_{2} \mathrm{Cl}_{3} /$ $\beta C D$ (punteada), d. mezcla física (gris).
Figura 3S. Curvas TGA para: a. $\beta C D$ (negra), b. [Ni(HAPTSC) $\left.{ }_{2}\right]$ $\mathrm{Cl}_{2}$ (discontinua), c. compuesto de asociación [Ni(HAPTSC) $\left.{ }_{2}\right] \mathrm{Cl}_{2} /$ $\beta C D$ (punteado), d. mezcla física (gris).

Figura 4S. Curvas TGA para: a. $\beta C D$ (negra), b. HAPTSC (discontinua), c. compuesto de asociación HAPTSC/ $\beta \mathrm{CD}$ (punteada), d. mezcla física (gris).

\section{Agradecimientos}

Los autores agradecen a la Dirección de Investigación Sede Bogotá (DIB) de la Universidad Nacional de Colombia por el apoyo financiero al proyecto $\mathrm{N}^{\circ}$. 201010016735. También se agradece al Profesor Milton Crosby, Departamento de Farmacia, Facultad de Ciencias, Universidad Nacional de Colombia, por facilitar las cepas utilizadas en los ensayos antimicrobianos.

\section{Conflicto de intereses}

Los autores declaran no tener conflicto de intereses.

\section{Bibliografía}

Anderson, F.E., Duca, C.J., \& Scudi, J.V. (1952) Some heterocyclic thiosemicarbazones. Journal of the American Chemical Society. 73: 4967-4968.

Beraldo, H. (2004) Semicarbazonas e tiossemicarbazonas: o amplio perfil farmacológico e usos clínicos. Química Nova. 27 (3): 461-471.
Beraldo, H., \& Gambino D. (2004). The wide pharmacological versatility of thiosemicarbazones, semicarbazones and their metal complexes. Mini Reviews in Medicinal Chemistry. 4 (1): 31-39.

Burgos, A.E., \& Sinisterra, R.D. (2010) Preparación y caracterización de compuestos de asociación entre el acetato, propionato y butirato de rodio(II) con $\beta$-ciclodextrina. Revista Colombiana de Química. 39: 427-445.

Burgos, A.E., Belchior, J.C., \& Sinisterra, R.D. (2002) Controlled release of rhodium(II) carboxylates and their association complexes with cyclodextrins from hydroxyapatite matrix. Biomaterials. 23 (12): 2519-2526.

Burgos, A.E., Okio, C.K.Y.A., Sinisterra, R.D. (2012) Preparação do composto de associação entre citrato de ródio(II) e $\beta$-ciclodextrina. Quimica Nova. 35 (4): 762-765.

Calderini, A., \& Pessine, F.B.T. (2008) Synthesis and characterization of inclusion complex of the vasodilator drug minoxidil with b-cyclodextrin. Journal of Inclusion Phenomena and Macrocyclic Chemistry. 60 (3-4): 369-377. 
Da Silva, A.M.M., Empis, J.M.A., \& Teixeira-Dias, J.J.C. (2002) Inclusion of carvone enantiomers in cyclomaltoheptaose ( $\beta$-cyclodextrin): thermal behaviour and $\mathrm{H} \rightarrow \mathrm{D}$ and $\mathrm{D} \rightarrow \mathrm{H}$ exchange. Journal of Carbohydrate Research. 337 (24): 2501-2504.

De Sousa, F., Leite, A., Lula, I., Nascimento, C., Fernandes, N., Lima, A., De Almeida, W., \& Sinisterra, R.D. (2008) Supramolecular Self-Assembly of Cyclodextrin and Higher Water Soluble Guest: Thermodynamics and Topological Studies. Journal of the American Chemical Society. 130 (26): 8426-8436.

Del Valle, E.M.M. (2004) Cyclodextrins and their uses: a review. Process Biochemistry. 39 (9): 1033-1046.

Giordano, F., Novak, C., \& Moyano, J.R. (2001) Thermal analysis of cyclodextrins and their inclusion compounds. Thermochimica Acta. 380 (2): 123-151.

Gupta, S.P. (1994) Quantitative structure-activity relationship studies on anticancer drugs. Chemistry Reviews. 94 (6): 1507-1551.

Inoue, Y. (1993) NMR Studies of the structure and properties of cyclodextrins and their inclusion complexes. Annual Reports on NMR Spectroscopy. 27: 59-101.

Kasuga, N.C., Sekino, K., Koumo, C., Shimada, N., Ishikawa, M., \& Nomiya, K. (2001) Synthesis, structural characterization and antimicrobial activities of 4- and 6-coordinate nickel(II) complexes with three thiosemicarbazones and semicarbazone ligands. Journal of Inorganic Biochemistry. 84 (1-2): 55-65

Kayaci, F., Ertas, Y., \& Uyar, T. (2013a) Enhanced thermal stability of eugenol by cyclodextrin inclusion complex encapsulated in electrospun polymeric nanofiber. Journal of Agricultural and Food Chemistry. 61 (34): 8156-8165.

Kayaci, F., Umu, O.C.O., Tekinay, T., \& Uyar, T. (2013b) Antibacterial Electrospun Poly(lactic acid) (PLA) Nanofibrous webs incorporating triclosan/cyclodextrin inclusion complexes. Journal of Agricultural and Food Chemistry. 61 (16): 3901-3908.

Kettel, M.J., Schaefer, K., Groll, J., \& Moeller, M. (2014) Nanogels with high active $\beta$-cyclodextrin content as physical coating system with sustained release properties. ACS Applied Materials \& Interfaces. 6 (4): 2300-2311.

Klayman, D.L., Bartosevich, J.F., Griffin, T.S., Mason, C.J., \& Scovill, J.P. (1979) 2-Acetylpyridine thiosemicarbazones. 1. A new class of potential antimalarial agents. Journal of Medical Chemistry. 22 (7): 855-862.

Kohata, S., Jyodoi, K., \& Ohyoshi, A. (1993) Thermal decomposition of cyclodextrins (a-, $\beta-$, g-, and modified $\beta-\mathrm{CD})$ complexes in the solid phase. Thermochimica Acta. 217: 187-198.

Kovala-Demertzi, D., Demertzis, M.A., Miller, J.R., Papadopoulou, C., Dodorou, C., \& Filousis, G. (2001) Platinum(II) complexes with 2-acetyl pyridine thiosemicarbazone. Synthesis, crystal structure, spectral properties, antimicrobial and antitumour activity. Journal of Inorganic Chemistry. 86 (2-3): 555-563.

Krishnan, K., Prathiba, K., Jayaprakash, V., Basu, A., Mishra, N., Zhou, B., Hu, S., \& Yen, Y. (2008) Synthesis and ribonucleotide reductase inhibitory activity of thiosemicarbazones. Bioorganic and Medicinal Chemistry Letters. 18 (23): 6248-6250.

Lobana, T.S., Sharma, R., Bawa, G., \& Khanna, S. (2009) Bonding and structure trends of thiosemicarbazone derivatives of metals-An overview. Coordination Chemistry Reviews. 253 (7-8): 977-1055.

Offiong, E., \& Martelli, S. (1997) Stereochemistry and antitumour activity of platinum metal complexes of 2-acetylpyridine thiosemicarbazones. Transition Metal Chemistry. 22 (3): 263-269.

Poveda, A., \& Jiménez-Barbero, J. (1998) NMR studies of carbohydrate-protein interactions in solution. Chemical Society Reviews. 27 (2): 133-144.

Reis, D.C., Pinto, M.C.X., Souza-Fagundes, E.M., Wardell, S.M.S.V., Wardell, J.L., \& Beraldo, H. (2010) Antimony(III) complexes with 2-benzoylpyridine-derived thiosemicarbazones: cytotoxicity against human leukemia cell lines. European Journal of Medicinal Chemistry. 45 (9): 3904-3910.

Ribero, L., Carvalho, R.A., Ferreira, C.D., \& Veiga, F.J.B. (2005) Multicomponent complex formation between vinpocetine, cyclodextrin, tartaric acid and water-soluble polymers monitored by NMR and solubility studies. European Journal of Pharmaceutical Sciences. 24 (1): 1-13.

Sharma, V.K., Srivastava, S., \& Srivastava,A. (2007) Spectroscopic, thermal and biological studies on some trivalent ruthenium and rhodium NS chelating thiosemicarbazone complexes. Bioinorganic Chemistry and Applications, 2007, 68374.

Sinisterra, R.D., Shastri, V.P., Najjar, R., \& Langer, R. (1999) Encapsulation and release of rhodium(II) citrate and its association complex with hydroxypropyl-b-cyclodextrin from biodegradable polymer microspheres. Journal of Pharmaceutical Sciences. 88 (5): 574-576.

Skoog, D.A., Holler, F.J., \& Nieman, T.A. (2001) Principios de análisis instrumental. (pp. 353-364). Madrid (España): McGraw Hill.

Steiner, T., \& Koellner, G. (1994) Crystalline Beta-cyclodextrin hydrate at various humidities: fast, continuous, and reversible dehydration studied by X-ray diffraction. Journal of the American Chemical Society. 116 (12): 5122-5128.

Szejtli, J. (1998) Introduction and general overview of cyclodextrin chemistry. Chemical Reviews. 98 (5): 1743-53.

Tamayo, L.V., Burgos, A.E., \& Brandão, P.F.B. (2014) Synthesis, characterization, and antimicrobial activity of the ligand 3-methylpyrazole-4-carboxaldehyde thiosemicarbazone and its Pd(II) complex. Phosphorus, Sulfur, and Silicon and the Related Elements. 189 (1): 52-59.

Tenório, R.P., Góes, A.J.S., de Lima, J.G., de Faría, A.R., Alves, A.J., \& de Aquino, T.M. (2005) Tiossemicarbazonas: métodos de obtenção, aplicações sintéticas e importância biológica. Química Nova. 28 (6): 1030-1037.

Wenz, G. (1994) Cyclodextrins as building blocks for supramolecular structures and functional units. Angewandte Chemie International Edition in English. 33 (8): 803-822. 